\title{
Nutritional programming by dietary carbohydrates in European sea bass larvae: not always what expected at juvenile stage
}

\author{
Zambonino Infante Jose-Luis ${ }^{1,{ }^{*}}$, Panserat $S^{2}$, Servili Arianna ${ }^{1}$, Mouchel Olivier ${ }^{1}$, Madec Lauriane ${ }^{1}$, \\ Mazurais David ${ }^{1}$
}

1 Ifremer, UMR 6539 LEMAR, PFOM-ARN, Centre de Bretagne, 29280 Plouzané, France

2 INRA, Univ. Pau \& Pays de l'Adour, E2S UPPA, UMR1419 Nutrition, Métabolisme, Aquaculture, Aquapôle, 64310 Saint-Pée-sur-Nivelle, France

*Corresponding author : Jose-Luis Zambonino Infante, email address : jose.luis.zambonino@ifremer.fr

\begin{abstract}
:
Optimizing the metabolic use of these carbohydrate-rich plant products in fish feeds could be achieved through nutritional programming strategies of fish larvae. The present study aims at testing the longterm effect of an early-life high-carbohydrate nutritional (34\% of starch in the feed) stimulus in European sea bass (Dicentrarchus labrax), by examining several biochemical and molecular parameters involved in carbohydrate metabolism in sea bass larvae and juveniles, compared to a control group fed standard larval regime (phase 1). As awaited, specific activities of digestive enzymes, from pancreatic and intestinal segments, involved in glucide digestion (amylase, sucrase) were enhanced together with an up-regulation of glucokinase gene and down-regulation of glucose 6-phosphatase gene assayed in whole-body larvae fed the high-carbohydrate diet. However, this regime also induced a significant lowering in growth and survival.

Six months later, while all the fish were fed the same standard diet, a first hypoxia challenge test allowed to distinguish two groups of fish according their nutritional history at larval stage: fish had been fed high-carbohydrate regime performed much better than control. When fed again during 2 months with a high-carbohydrate diet (phase 2), such larval nutritional history did not confer any subsequent "advantage" or "disadvantage" in term of carbohydrate metabolism and growth. A second hypoxia challenge test performed just after phase 2, did not confirm the first one. All together our results indicated that the larval conditioning may fade over time. It was suggested to apply regular nutritional stress pulses during the first months of fish life.
\end{abstract}




\section{Highlights}

- A trial to achieve a nutritional programming of the carbohydrate metabolic pathways was conducted on European sea bass larvae from first feeding. Six months later, while all the juvenile fish were fed the same standard diet, a challenge test allowed to evidence that fish having been fed highcarbohydrate regime at larval stage performed much better than control. After two months of feeding again with a high-carbohydrate diet, such larval nutritional history did not confer any subsequent "advantage" or "disadvantage" to juveniles. A second challenge test performed just after indicated that the larval conditioning may fade over time, which should prompt us to reconsider the standard programming strategy used in fish.

Keywords : Dicentrarchus labrax, Glucose metabolism, High-carbohydrate regimes, Marine fish larvae, Nutritional programming 


\section{Introduction}

The possibility of metabolic programming during critical stages of early-life has received a lot of interest over the last 20 years (Lucas et al., 1998; Patel and Srinivasan, 2002; Pittman et al., 2013). This programming results from an alteration of the functional development of crucial organs in response to environmental and trophic conditions encountered ( Demmelmair et al., 2006; Hamdoun and Epel, 2007). In most of the cases, these functional changes remain permanent and could be considered as an "adaptive tuning" in order to adjust the animal physiology to the environments likely to be encountered in later life (Hamdoun and Epel, 2007; Wadhwa et al, 2009; Calder et al., 2010).

Beyond the medicine interest generated by this research area (Harding, 2005), many other studies focused on the development of new feeding strategies based on the implementation of the "programming concept" in animal production and more specifically in aquaculture (Geurden et al., 2007; Vagner et al., 2007; Gotoh, 2015; Turkmen et al., 2017). Indeed, fish aquaculture urgently needs to lower its over-dependence on fishmeal and fishoil, which are mainly provided by fisheries and do not offer a sustainable perspective considering both the capture stagnation and depletion of marine resources (FAO, 2016). Aquafeeds substituting significant amount of marine products by plant-based ingredients are available (Naylor et al., 2009); however, it is still challenging to totally lower the aggregate level of fish oil and meal because plant feedstuffs possess different nutritional characteristics, the two majors being probably the fact they do not contain essential long-chain omega 3 fatty acids and are naturally rich in carbohydrates (Naylor et al., 2009). This is challenging because on one hand, marine fish do not possess efficient/functional elongation and desaturation capacity to convert $\alpha$-linolenic acid into essential long-chain omega 3 fatty acids (Castro et al., 2016) and, on the other hand, carbohydrates are poorly metabolized by carnivorous fish which restricted the use of carbohydrates in aquafeeds (Enes et al., 2009; Polakof et al., 2012; Kamalam et al., 2017). In this context, the possibility of making functional (or enhancing) some metabolic pathways in juvenile or adult fish by a specific nutritional programming at early-life stages is of great interest. Nutritional programming tests with high-carbohydrate diets were so far mostly performed on rainbow trout (Oncorhynchus mykiss). These studies clearly demonstrated that an early-nutritional stimulus led to persistent changes at juvenile stage in genes and enzymes involved in carbohydrate digestion (Geurden et al., 2007), glucose transport and metabolism (Geurden et al., 2007; Geurden et al., 2014; Liu et al., 2017). However, these studies also revealed that the early-life nutritional programming in rainbow trout did not induce a clear benefit in carbohydrate metabolism; as a matter of fact, it did not produce similar and constant responses even when they are indicative of the same physiological function, since not always the same physiological markers were modulated, and not always the same tissues/organs were concerned by the long-lasting changes. One can wonder 
whether these heterogeneous responses mainly reflect, as early as the beginning of the exogenous feeding in rainbow trout alevins, the existence of a buffering capacity of the gene regulatory networks involved in the carbohydrate digestion and metabolism. Corollary, it can be wondered whether the nutritional programming does not come at a (too?) advanced developmental stage in this fish species? In addition, it is unknown whether such heterogeneous responses could have led to physiological trade-offs with potential effects at the organism scale.

A track to address these different issues could be to consider another carnivorous species, like European sea bass (Dicentrarchus labrax), a marine fish that hatches at an earlier developmental stage than many freshwater species (Barnabé et al., 1976; Villeneuve et al., 2005) and could be fed microparticulate feeds from mouth opening, before the resorption of vitellus. In the present study, our first objective was to test the long-term effect of an early-life high-carbohydrate nutritional stimulus, on several biochemical and molecular parameters involved in carbohydrate metabolism in sea bass larvae and juveniles. Second, we sought to evaluate the long-term effect of this early-life stimulus at the organism scale by examining individual fish tolerance to an acute challenge test.

\section{Material and Methods}

\subsection{Ethics}

The present work was performed within Ifremer-Centre de Bretagne facilities (agreement number: B29-212-05). Experiments were performed under French national regulations and approved by the Comité d'Éthique Finistérien en Expérimentation Animale (CEFEA, registration code C2EA-74) (Authorization APAFIS 1965.09).

\subsection{Rearing conditions and experimental design}

Sea bass (Dicentrarchus labrax) larvae, at 2 days post-hatching (dph), were obtained from a commercial hatchery (Ploemeur, France), and experiments were conducted at the Ifremer-Centre Bretagne (Plouzané, France). The experimental design (already described in Gatesoupe et al. (2016)) is schematized in Figure 1.

Phase 1: This first phase aimed at performing a nutritional conditioning to first-feeding larvae. Larvae were distributed in ten conical fiberglass tanks (35litres; initial stocking density was sixty larvae per litre, i.e. 2100 larvae per tank) and temperature was progressively increased from $14^{\circ} \mathrm{C}$ to $20^{\circ} \mathrm{C}$ within 2 days. Throughout the experiment, salinity was $35 \%$, and the oxygen level was maintained above $6 \mathrm{mg} \mathrm{L}^{-1}$ by setting the water replacement in the tank at up to $30 \%$ per hour (flow rate: $0.18 \mathrm{~L}$ $\min ^{-1}$ ). Photoperiod was $12: 12 \mathrm{~h}$ light:dark cycle, and light intensity was progressively increased (up to $15 \mathrm{~mW} \mathrm{~m}^{-2}$ from day 2 to day 27 , and then up to $96 \mathrm{~mW} \mathrm{~m}^{-2}$ until day 45). All groups were fed microparticulate diets from mouth opening at day 6 to day 29. Two experimental diets were tested in 
5 replicates: high level of carbohydrate (diet HG) and control diet (diet C; Table 1). HG diet was distributed until day 23 , and replaced by the Control diet. This date was chosen during the timecourse of the experiment, to avoid likely strong mortality episodes. At day 29, the 2 feeds were replaced by Artemia nauplii according to Zambonino-Infante et al. (1996). At day 45, larvae from a similar group were pooled together in one 450-L tank, and fed a Transition diet (diet T; Table 1). Larval survival was determined by counting all the individuals.

At 202 dph, a PIT-tag (PIT: passive integrated transponder) was subcutaneously implanted using a needle (diameter of about $1.5 \mathrm{~mm}$ ) in an anterodorsally position, halfway between the head and the first dorsal fin; We tagged 300 individuals per group (individual mean weights were 16.6 and $15.4 \mathrm{~g}$ in groups $\mathrm{C}$ and $\mathrm{HG}$, respectively). Other fish were not kept for the present study.

Phase 2: This second phase aimed at repeating with fish juveniles the initial nutritional conditioning done in phase 1 with larvae, with diet T and diet HG2 (30\% of the protein sources were replaced by starch) (Table 1). Three new experimental groups were then randomly constituted in two 450-L tanks: a/ fish fed diet T: 200 fish from control group, and designated as C-T (new control group for this second phase); b/fish fed diet HG2: 100 fish from control group and 100 fish from HG group, and designated as C-HG2 and HG-HG2 respectively. From day 227, the fish were fed these experimental diets for two months until the end of the experiment (day 287).

\subsection{Samplings and growth monitoring}

\subsubsection{Phase 1:}

Fifty larvae were collected from each tank for enzymatic studies before morning food distribution; larvae were pooled, killed with an excess of anesthetic ( $200 \mathrm{mg} \mathrm{L}^{-1}$ Tricaïne methanesulfonate, TMS, Pharmaq, Fordingbridge, Hampshire, UK) and immediately stored at $-80^{\circ} \mathrm{C}$ pending dissection and assays. Dissections under microscope were done on a glass maintained at $0^{\circ} \mathrm{C}$; larvae were cut as described by Cahu and Zambonino-Infante (1994), and only pancreatic and intestinal segments were kept for enzymatic assays.

Larvae for RNA extraction were sampled at day 20, i.e. just before the diet change that was done for HG group. Fifty mg of larvae (which represents a number of larvae ranging from 15 to 20) were collected from each tank and killed with an excess of anesthetic ( $\left.200 \mathrm{mg} \mathrm{L}^{-1} \mathrm{TMS}\right)$. They were pooled into tubes containing RNA-later (Qiagen, Hilden, Germany) and placed at $4^{\circ} \mathrm{C}$ for $24 \mathrm{~h}$, then kept at $-20^{\circ} \mathrm{C}$ until total RNA extraction.

To monitor growth, 10 larvae pertank ( $n=5$ tanks for each dietary group) were taken at day 45 , after lowering the tank water volume; the 10 larvae were collected in one time using an appropriate net. Larvae were killed with an excess of anesthetic ( $200 \mathrm{mg} \mathrm{L}^{-1} \mathrm{TMS}$ ) and fixed in formaldehyde for fixation ( $4 \%$ final concentration) until individual mass measurement. 


\subsubsection{Phase 2:}

Tissue and blood samplings were performed at day 287; Juvenile fish left undisturbed and unfed for $24 \mathrm{~h}$. Twelve juveniles from each groups (i.e. C-T, C-HG2 and HG-HG2) were randomly selected and lightly anesthetized ( $150 \mathrm{mg} \cdot \mathrm{L}^{-1} \mathrm{TMS}$ ). Sample of blood (1 mL per individual) was drawn from their caudal vein using a heparinized syringe and divided between two tubes for hematocrit (Hct) and plasma metabolites (glucose and lactate) analyses. The fish were then killed with an excess of anesthetic (500 mg. $\mathrm{L}^{-1} \mathrm{TMS}$ ) and tissues (liver and intestine) were immediately dissected. Samples were weighed, quickly placed in liquid nitrogen and then were kept at $-80^{\circ} \mathrm{C}$ until further molecular and biochemical analyses. Liver samples were individually cryo-grinded to be further used for molecular and biochemical analyses.

Each juvenile from C-T, C-HG2 and HG-HG2 groups was weighed at day 225 and 287 after a light anesthesia (150 $\mathrm{mg} \cdot \mathrm{L}^{-1} \mathrm{TMS}$ ).

\subsection{Hypoxia Challenge tests (HCT)}

Two hypoxia challenges tests were performed just before (day 220, i.e. 7.3 months) and after the phase 2 (day 292, i.e. 9.7 months after hatching), as described by Vanderplancke et al. (2015). All tagged fish were pooled in a single tank $\left(2 \mathrm{~m}^{3}\right)$, left undisturbed and unfed for 48 hours. Water oxygenation was then decreased from $100 \%$ to $10 \%$ within one hour by bubbling nitrogen gas in the tank, followed by a slower descent at $1.2 \%$.hour ${ }^{-1}$ to $4 \%$; dissolved $\mathrm{O}_{2}$ was constantly and precisely monitored. As fish lost their equilibrium, they were removed, identified (PIT-tag reading) and quickly placed in fully aerated conditions in their respective tank. The corresponding time (hypoxia resistance time, HRT) and oxygenation level were recorded. The HCT ended when the last fish was replaced in aerated conditions.

\subsection{Blood and liver biochemical analyses}

Hematocrit, glucose and lactate were measured in fish blood. Hematocrit was measured using heparinized micro-capillaries (Becton Dickinson \& Co, NJ, USA, ref 361021); Powdered livers were resuspended in sodium-citrate buffer and glycogen was transformed into glucose after hydrolysis by amyloglucosidase (Sigma-Aldrich A-9228). Commercial kits were used for measuring glucose (Glucose GOD-PAP ref LP80209, from Abliance, Compiègne, France) and lactate (Lactate ref LC2389, from Randox, Roissy-en-France, France) levels on blood plasma.

\subsection{Enzymatic assays}

The pancreatic segments were homogenized into 5 volumes $(\mathrm{v} / \mathrm{w}$ ) of ice-cold distilled water. Trypsin and amylase activities were assayed according to Holm et al. (1988) and Métais and Bieth (1968), 
respectively. Glucose 6-Phosphate Dehydrogenase (G6PDH) in liver was assayed according to Noltmann et al. (1961). Sucrase from the intestinal brush border membrane was assayed according Dahlqvist (1970). Purified brush border membranes from the intestinal segment homogenate were obtained according to a method developed for intestinal scraping (Crane et al. 1979). Enzyme activities were expressed as specific activities, i.e. $\mu$ moles of hydrolys ed substrate for sucrase and trypsin. Amylase activity was expressed as the equivalent enzyme activity required for hydrolyzing 1 $\mathrm{mg}$ of starch during $30 \mathrm{~min}$ at $30^{\circ} \mathrm{C}$. Proteins were determined by the Bradford procedure (Bradford, 1976).

\subsection{Gene expression assays}

RNA extraction required for gene expression analysis in Phase 1 and Phase 2 was performed using fifty mg of larvae or powdered liver, respectively. Total RNA was extracted in extract-all reagent (Eurobio; Courtaboeuf, Essonne, France) combined with nucleospin RNA kit (Macherey Nagel, Düren, Germany) following recommendations from the supplier. The quantity and quality of extracted RNA were assessed using a ND-1000 NanoDrop ${ }^{\circledR}$ spectrophotometer (Thermo Scientific Inc.; Waltham, MA, USA) and an Agilent Bioanalyser 2100 (Agilent Technologies Inc.; Santa Clara, CA, USA), respectively. All RNA samples exhibited a RNA integrity number (RIN) higher than eight and could thus be used for real-time quantitative PCR ( $Q P C R$ ) analysis. RNA samples were stored at $-80^{\circ} \mathrm{C}$ until cDNA synthesis (reverse transcription).

Reverse transcription was carried out using $500 \mathrm{ng}$ of RNA with an iScript ${ }^{\mathrm{TM}}$ CDNA Synthesis kit (BioRad Laboratories Inc.; Hercules, CA, USA) following supplier's recommendations. Resulting cDNA was stored at $-20^{\circ} \mathrm{C}$ until use. RT negative controls (same reaction mix without reverse transcriptase) were performed on each sample.

qPCR was performed using the primers listed in Table 2. Primers were designed using Primer3plus (http://primer3plus.com/), based on cDNA sequences [Glucose-6 phosphatase (g6pc), Glucokinase (gck) and Elongation factor-1 alpha (ef1 $1 \alpha$ )] available from the NCBI (https://www.ncbi.nlm.nih.gov/). Gene expression was quantified using an iCycler MyiQ ${ }^{\mathrm{TM}}$ Single Color Real-Time PCR Detection System (BioRad Laboratories Inc.). Efficiencies of amplification were validated for each primer pair using serial dilutions from a pool of cDNA. Reaction with performed in a final well volume of $15 \mu \mathrm{L}$, containing $5 \mu \mathrm{L}$ of diluted cDNA (1/10) and $10 \mu \mathrm{L}$ of reaction mix, composed of $0.5 \mu \mathrm{L}$ of each primer (10 mM), $1.5 \mu \mathrm{L}$ RNase/DNase free water, $7.5 \mu \mathrm{L} \mathrm{iQ}^{\mathrm{TM}} \mathrm{SYBR}^{\circledR}$ Green Supermix (BioRad Laboratories Inc.) containing antibody-mediated hot-started iTaq DNA polymerase, dNTPs, $\mathrm{MgCl} 2$, SYBR ${ }^{\circledR}$ Green I dye, enhancers, stabilizers and fluorescein. Each sample was run in triplicate. Negative controls (nontemplate control) as well as RT negative controls were systematically included in each plate. The qPCR protocol included an initial activation step at $95^{\circ} \mathrm{C}$ for $2 \mathrm{~min}$, followed by $39 \mathrm{cycles}: 5 \mathrm{~s}$ at $95^{\circ} \mathrm{C}$ 
and $20 \mathrm{~s}$ at $60^{\circ} \mathrm{C}$. After the amplification phase, a melting curve was performed to confirm the amplification of a single product for each reaction.

For each sample, the corresponding Cq (Quantification cycle) value was determined aut omatically using the "Gene Expression Module" of CFX Manager software (BioRad Laboratories Inc.). The relative quantity of messenger was normalized with the $\Delta \Delta C \mathrm{C}$ method. The elongation factor 1-alpha (ef1 $\alpha$ ) gene was used as reference gene since it did not show any significant variation of expression between samples (relative standard deviation $<5 \%$ among samples).

\subsection{Statistical analyses}

Statistical analyses were performed using STATISTICA software version 10 (http://statsoft.fr/). All data were log-transformed to fit a normal distribution. For all analyses, variables were checked for normality (Shapiro test) and equality of variances (Levene test). Significant differences in growth, survival, hematological parameters, digestive enzymes and gene expression were compared using an independent two group t-test.

Time of resistance to hypoxia during HCT was analyzed using survival analysis techniques. Therefore, the proportion of individuals resisting to hypoxia as a function of time, together with its $95 \%$ confidence intervals, was estimated using a Kaplan-Meier method. Then, we used a Cox-Mantel test to describe how the hazard rate, i.e., the rate of occurrence of the loss of equilibrium, was affecte $d$ by the dietary regime.

\section{Results}

\subsection{Phase 1}

At day $20, \mathrm{HG}$ diet induced significant $35 \%$ and $18 \%$ increases in amylase and sucrase specific activities respectively, compared to the control group (Table 3). Conversely, trypsin specific activity was significantly lowered by $50 \%$ in HG group compared to the control (Table 3).

Expression of Glucokinase was 2.6 times higher in HG larvae compared to control larvae (Table 3); Conversely, Glucose- 6 phosphatase mRNA level was 1.43 times higher in control larvae than in HG ones (Table 3).

At day 45 , survival $(53.4 \pm 15.05 \%$ vs $31.8 \pm 16.3 \% ; p=0.018)$ and final mass $(37.4 \pm 0.61 \mathrm{mg}$ vs $27.2 \pm 0.45$ mg; $p<0.0001$ ) of control larvae were significantly higher than that of HG group.

At day 220, juvenile fish that were fed HG diet during the larval period exhibited a better tolerance to hypoxia than control fish ( $p=0.011$; Figure 2 ). In particular, the time necessary to reach $50 \%$ of the population was 2.84 vs 2.62 hours for HG and control groups respectively, i.e. a difference in tolerance higher than 13 minutes; the difference in tolerance time increased up to 30 minutes when considering $90 \%$ of the population. 


\subsection{Phase 2}

After nearly 2 months of feeding, final masses were not significantly different between the 3 dietary groups, even though the HG-HG2 group exhibited a slightly higher growth the beginning of the experiment (Table 4). Hematocrit and plasma lactate values were not significantly different between the 3 dietary groups ( $p>0.05$; Table 4). Plasma glucose concentration was nearly 2 times higher in fish fed HG2 diet rather than T diet ( $p=6.10^{-5}$; Table 4); alike, 50\% higher levels of glycogen were also found in liver of fish fed HG2 diet ( $p=2.10^{-5}$; Table 4). Specific activities of Glucose-6-phosphate dehydrogenase in liver and sucrase in intestine were increased by nearly $85 \%$ in C-HG2 and HG-HG2 dietary groups compared to $\mathrm{C}-\mathrm{T}$ one ( $p=3.10^{-5}$ for G6PDH and $p=10.10^{-5}$ for sucrase; Table 4). Glucose6 phosphatase gene expression was significantly higher in C-T group compared to C-HG2 (2.6 times lower) and HG-HG2 (4 times lower) groups ( $p=10^{-5}$; Table 4). No significant difference was found in Glucokinase gene expression between the 3 dietary groups.

The only significant difference in hypoxia tolerance was found between C-T and C-HG2 groups $(p=0.003$; Figure 3), the latter exhibiting a better tolerance performance (13 minutes and 17 minutes more when reaching $50 \%$ and $90 \%$ of the population, respectively). No significant difference was revealed between C-T and HG-HG2 $(p=0.244)$ on one hand, and between HG-HG2 and C-HG2 $(p=0.151)$ on the other hand.

\section{Discussion}

Most of marine fish larvae species hatch at very early developmental stage which does not ease the use of formulated diets in substitution for live preys before a certain date in fish hatcheries, usually third week of life in hatchery for temperate species (Cahu and Zambonino-Infante, 2001). The European sea bass can be fed microparticulated diets as early as mouth opening (Cahu et al., 2003) which constitutes a real advantage for examining the effects of an early nutritional conditioning. The present study was then conceived to evaluate how a marine carnivorous fish, Dicentrarchus labrax, physiologically responds to a high-carbohydrate nutritional conditioning that occurred during the larval period. Specifically, we formulated a $34 \%$ high-carbohydrate diet where approximatively $15 \%$ of the proteins were substituted by digestible starch because it was risky to go beyond this substitution rate without seriously jeopardizing larval growth and survival. Following the same logic, after 18 days of feeding this high-carbohydrate diet, we decided to switch to another more adequate nutritional regime at $23 \mathrm{dph}$ in order to avoid strong mortality episodes. It has to be pointed out that $20 \%$ dietary starch is thought to be close to the maximum tolerable for sea bass juveniles (Moreira et al., 2008).

These 18 days of high-carbohydrate feeding were largely enough to significantly enhance the specific activities of digestive enzyme involved in glucide digestion parallel to a lowering in trypsin specific 
activity. Such modulations of amylase and trypsin activities in direct relation to the dietary starch level were awaited, as it has already been reported by Péres et al. (1996) in sea bass larvae older than $18 \mathrm{dph}$.

Not surprisingly, in HG-group we also observed an up-regulation of glucokinase gene, which enzyme acts as a sensor of high glucose-levels in the body and catalyzes the phosphorylation of glucose to glucose-6-phosphate, first step of the hepatic glycogen synthesis (Enes et al, 2009). Conversely, glucose 6-phosphatase gene whose enzyme facilitates glucose release (Enes et al, 2009) was downregulated in HG larvae. Similar gene regulations were also reported for glucokinase and glucose 6phosphatase in European sea bass juveniles fed dietary starch levels from $10 \%$ to $20 \%$ (Enes et al., 2008; 2009), but have never been examined at larval stages.

These changes in enzyme activities and gene expression clearly illustrated the short-term plasticity of $20 \mathrm{dph}$ larvae fed a high-carbohydrate regime. However, this adaptive-tuning to such a diet had likely a metabolic cost which could explain the lower survival and growth at the end of the larval period compared to the control dietary group. It has to be pointed out that similar effects on growth have been reported for rainbow trout larvae fed a hyperglucidic diet (Geurden et al., 2007) even though survival rates were much higher with this species (Geurden et al., 2014). The low survival observed in the present study in larvae fed the high-carbohydrate diet ( $40 \%$ lower than that of the control) does not exclude that a possible genetic selection has been carried out in this group, although this was not targeted; this point should be considered if any nutritional conditioning is observed at the juvenile stage.

After the larval period, when favorable nutritional conditions were restored with diet $\mathrm{T}$, fish that have been fed the high-carbohydrate regimelikely entered in a phase of compensatory growth (Ali et al., 2003), which could simply explain the higher mass of this group of fish at the end of phase 1. Almost six months after the larval period, while all the fish were fed the same regime $(\operatorname{diet} T)$, the hypoxia challenge test allowed to distinguish two groups of fish according their nutritional history at larval stage: fish having been fed high-carbohydrate regime performed much better than control. The resistance of fish to such hypoxic challenge depends on their capacity to optimize oxygen extraction and transport, as well as their ability to regulate several physiological processes related to cardiovascular functions and energy metabolism (Roze et al., 2013). This hypoxia challenge test gives then a global evaluation of fish physiological status. Differential performance of fish to such challenge test strongly suggested that nutritional conditions encountered during the early-period of the larvae life have differentially shaped the physiology of the resulting fish without, however, excluding the possibility of genetic selection as mentioned above. Under hypoxia, anaerobic metabolism increases the demand for glucose substrate (Richards, 2009) which could be possibly better supplied by fish having a high-carbohydrate nutritional history. Then, it could be wondered 
whether this means that fish having experienced the high-carbohydrate regime during the larval period better metabolize dietary glucides than control fish.

The second phase of the present study was set up to examine this issue by comparing a highcarbohydrate feed (HG2) to a low-carbohydrate one (T). Although we cannot exclude an effect of dietary protein level (53\% vs $40 \%$ for T and HG2 diets) on the regulation of glucose metabolism, the presence at high level versus very low level of dietary digestible carbohydrate (starch) was the major difference between the two T and HG2 diets which could impact this metabolism. From a growth point of view, the high-carbohydrate regime during the sea bass larval period did not confer any subsequent "advantage" or "disadvantage" when fish were fed again a high-carbohydrate diet for two months; Similar growth performances have been generally reported for rainbow trout juveniles (Geurden et al., 2007; 2014) that have been fed high-glucide diets compared to a conventional diet during their larval period; however, lesser growth performance can also be observed (Liu et al., 2017). Globally, these results indicate that the early-life stimulus with hyperglucidic diets did not translate into growth advantage when fish were fed again high-carbohydrate diets at later life-stages. From a metabolic point of view, when fed the high-carbohydrate diet, juvenile sea bass exhibited similar glycaemia, hepatic glycogen content, sucrase and glucose-6-phosphate dehydrogenase activities whatever their nutritional history. In addition, we were also unable to detect any effect of the nutritional history on glucose- 6 phosphatase or glucokinase gene expression. These findings clearly indicated that the early high-carbohydrate stimulus did not specifically change the normal response to dietary glucides observed in fish (Enes et al., 2008 and 2009; Castro et al., 2016).

Even more, the second hypoxia challenge test did not confirm the first one, i.e. fish having experienced the early-life high-carbohydrate nutritional regime did not perform better than the other fish. On the contrary, it appeared that fish fed the high-carbohydrate diet and having a conventional nutritional history tended to be the best performers. This last observation allows us to rule out the possibility of genetic selection on carbohydrate metabolism during the larval phase. Globally, our findings clearly showed that carbohydrate-stimulated sea bass at early-life stages did not perform better when fed high carbohydrate feeds, so that the support for the possibility of a permanent nutritional programing by carbohydrates in this species is quite limited. However, we cannot deny the fact that early conditioning with carbohydrates had effects on sea bass physiology visible up to 6 months after the early-stimulus as demonstrated by the first challenge test. We are therefore faced with a situation where the early-nutritional stress has triggered out a developmental plasticity that seemed to have been gradually erased, with a return to the "optimal" phenotype. This variation in the sea bass physiological response could be explained by the canalization hypothesis (Waddington, 1942; Stearns et al., 1995). Canalization hypothesis postulates that phenotypic variation is reduced by mechanisms against variations of the environment (in the broad sense), 
particularly when phenotypes are important for fitness. There is no doubt that carbohydrate metabolism is decisive for fitness, but promoting it too much in a carnivorous fish may have a metabolic cost that could have repercussions on other metabolic pathways just as important for fitness. This metabolic cost may have been perceived by the organism as unjustified, particularly during the transition phase without dietary glucides, which may have reinforced the triggering of canalization mechanisms. Several short nutritional stimuli with high-carbohydrate feeds over a period of a few months after the early-life conditioning could possibly stabilize the phenotype, which would represent a new approach for nutritional programming in fish.

\section{Conclusions}

This study shows that developmental plasticity does exist in marine fish because a different phenotype is visible through an acute-challenge several months after the early-life conditioning event. However, as exemplified by our results, this conditioning could be not permanent and may fade over time. Nutritional conditioning strategies for marine fish larvae should therefore take into account this possibility and perhaps should consider regular nutritional stress pulses during the first months of fish life to assess whether phenotype stabilization is achieved.

\section{Conflicts of interest}

The authors declared no conflict of interest.

\section{Acknowledgements}

This work was supported by the Commission of the European Communities, specific RTD programme of Framework Programme 7 (project FP7-KBBE-2011-5, ARRAINA project no. 288925, Advanced Research Initiatives for Nutrition and Aquaculture).

\section{References}

Ali, M., Nicieza, A., Wootton, R.J., 2003. Compensatory growth in fishes: a response to growth depression. Fish and Fisheries. 4, 147-190. https://doi.org/10.1046/j.1467-2979.2003.00120.x.

Barnabe, G., Boulineau-Coatanea, F., Rene, F., 1976. Chronologie de la morphogenese chez le loup ou bar Dicentrarchus labrax (L.) (Pisces, Serranidae) obtenu par reproduction artificielle. Aquaculture. 8, 351-363. https://doi.org/10.1016/0044-8486(76)90117-4.

Bradford, M.M., 1976. A rapid and sensitive method for the quantitation of microgram quantities of protein utilizing the principle of protein-dye binding. Anal Biochem. 72, 248-254.

https://doi.org/10.1016/0003-2697(76)90527-3 
Cahu, C.L., Zambonino Infante, J.L., 1994. Early weaning of sea bass (Dicentrarchus labrax) larvae with a compound diet: Effect on digestive enzymes. Comp Biochem Physiol A. 109A, 213-222. https://doi.org/10.1016/0300-9629(94)90123-6.

Cahu, C., Zambonino Infante, J.L., 2001. Substitution of live food by formulated diets in marine fish larvae. Aquaculture. 200 (1-2) Special Iss. SI, 161-180. https://doi.org/10.1016/S00448486(01)00699-8.

Cahu, C.L., Zambonino Infante, J.L., Barbosa, V., 2003. Effect of dietary phospholipid level and phospholipid : neutral lipid value on the development of sea bass (Dicentrarchus labrax) larvae fed a compound diet. Brit J Nutr. 90, 21-28. https://doi.org/10.1079/BJN2003880

Castro, C., Corraze, G., Firmino-Diogenes, A., Larroquet, L., Panserat, S., Oliva-Teles, A., 2016. Regulation of glucose and lipid metabolism by dietary carbohydratelevels and lipid sources in gilthead sea bream juveniles. Brit J Nutr. 116, 19-34. https://doi.org/10.1017/s000711451600163x.

Crane, R.K., Boge, G., Rigal, A., 1979. Isolation of brush border membranes in vesicular form from the intestinal spiral valve of the small dogfish (Scyliorhinus canicula). Bba-Biomembranes. 554, 264-267. https://doi.org/10.1016/0005-2736(79)90024-5.

Dahlqvist, A., 1970. Assay of intestinal disaccharidases. Enzymol biol clin. 11, 52-66.

Demmelmair, H., von Rosen, J., Koletzko, B., 2006. Long-term consequences of early nutrition. Early Hum Dev. 82, 567-574. https://doi.org/10.1016/j.earlhumdev.2006.07.004.

Enes, P., Panserat, S., Kaushik, S., Oliva-Teles, A., 2008. Rearing temperature enhances hepatic glucokinase but not glucose-6-phosphatase activities in European sea bass (Dicentrarchus labrax) and gilthead sea bream (Sparus aurata) juveniles fed with the same level of glucose. Comp Biochem Physiol A. 150, 355-358. https://doi.org/10.1016/j.cbpa.2008.04.596.

Enes, P., Panserat, S., Kaushik, S., Oliva-Teles, A., 2009. Nutritional regulation of hepatic glucose metabolism in fish. Fish Physiol Biochem. 35, 519-539. https://doi.org/10.1007/s10695-008-9259-5.

Gatesoupe, F.-J., Huelvan, C., Le Bayon, N., Le Delliou, H., Madec, L., Mouchel, O., Quazuguel, P., Mazurais, D., Zambonino-Infante, J.-L., 2016. The highly variable microbiota associated to intestinal mucosa correlates with growth and hypoxia resistance of sea bass, Dicentrarchus labrax, submitted to different nutritional histories. BMC Microbiology. 16, 266. https://doi.org/10.1186/s12866-0160885-2.

Geurden, I., Aramendi, M., Zambonino-Infante, J., Panserat, S., 2007. Early feeding of carnivorous rainbow trout (Oncorhynchus mykiss) with a hyperglucidic diet during a short period: effect on dietary glucose utilization in juveniles. Am J Physiol Regul Integr Comp Physiol. 292, R2275-2283. https://doi.org/10.1152/ajpregu.00444.2006.

Geurden, I., Mennigen, J., Plagnes-Juan, E., Veron, V., Cerezo, T., Mazurais, D., Zambonino-Infante, J., Gatesoupe, J., Skiba-Cassy, S., Panserat, S., 2014. High or low dietary carbohydrate:protein ratios during first-feeding affect glucose metabolism and intestinal microbiota in juvenile ra inbow trout. J Exp Biol. 217, 3396-3406. https://doi.org/10.1242/jeb.106062. 
Gotoh, T., 2015. Potential of the application of epigenetics in animal production. Animal Production Science. 55, 145-158. https://doi.org/10.1071/AN14467.

Hamdoun, A., Epel, D., 2007. Embryo stability and vulnerability in an always changing world. P Natl Acad Sci USA. 104, 1745-1750. https://doi.org/10.1073/pnas.0610108104.

Holm, H., Hanssen, L.E., Krogdahl, A., Florholmen, J., 1988. High and low inhibitor soybean meals affect human duodenal proteinase activity differently: in vivo comparison with bovine serum albumin. J Nutr. 118, 515-520. https://doi.org/10.1093/jn/118.4.515

Kamalam, B.S., Medale, F., Panserat, S., 2017. Utilisation of dietary carbohydrates in farmed fishes: New insights on influencing factors, biological limitations and future strategies. Aquaculture. 467, 327. https://doi.org/10.1016/j.aquaculture.2016.02.007.

Liu, J., Dias, K., Plagnes-Juan, E., Veron, V., Panserat, S., Marandel, L., 2017. Long-term programming effect of embryonic hypoxia exposure and high-carbohydrate diet at first feeding on glucose metabolism in juvenile rainbow trout. J Exp Biol. 220, 3686. https://doi.org/10.1242/jeb.161406

Lucas, A., 1998. Programming by Early Nutrition: An Experimental A pproach. J. Nutr. 128, 401S-406S. https://doi.org/10.1093/jn/128.2.401S

Métais, P., Bieth, J., 1968. Détermination de l'a-amylase par une microtechnique. Ann Biol Clin-Paris. 26, 133-142.

Moreira, I.S., Peres, H., Couto, A., Enes, P., Oliva-Teles, A., 2008. Temperature and dietary carbohydrate level effects on performance and metabolic utilisation of diets in European sea bass (Dicentrarchus labrax) juveniles. Aquaculture. 274, 153-160. https://doi.org/10.1016/j.aquaculture.2007.11.016.

Naylor, R.L., Hardy, R.W., Bureau, D.P., Chiu, A., Elliott, M., Farrell, A.P., Forster, I., Gatlin, D.M., Goldburg, R.J., Hua, K., Nichols, P.D., 2009. Feeding aquaculture in an era of finite resources. P Natl Acad Sci USA. 106, 15103. https://doi.org/10.1073/pnas.0905235106

Noltmann, E.A., Gubler, C.J., Kuby, S.A., 1961. Glucose 6-Phosphate Dehydrogenase (Zwischenferment) : I. Isolation of the crystalline enzyme from yeast. J Biol Chem. 236, 1225-1230.

Patel, M.S., Srinivasan, M., 2002. Metabolic Programming: Causes and Consequences. J. Biol. Chem. 277, 1629-1632. https://doi.org/10.1074/jbc.R100017200.

Peres, A., Cahu, C.L., Zambonino Infante, J.L., Le Gall, M.M., Quazuguel, P., 1996. Amylase and trypsin responses to intake of dietary carbohydrate and protein depend on the developmental stage in sea bass (Dicentrarchus labrax) larvae. Fish Physiol Biochem. 15, 237-242.

https://doi.org/10.1007/bf01875574.

Pittman, K., Yúfera, M., Pavlidis, M., Geffen, A.J., Koven, W., Ribeiro, L., Zambonin o-Infante, J.L., Tandler, A., 2013. Fantastically plastic: fish larvae equipped for a new world. Reviews in Aquaculture. 5, S224-S267. https://doi.org/10.1111/raq.12034.

Polakof, S., Panserat, S., Soengas, J.L., Moon, T.W., 2012. Glucose metabolism in fish : a review. Journal of Comparative Physiology B. 182, 1015-1045. http://dx.doi.org/10.1007/s00360-012-0658-7. 
Richards, J.G., 2009. Chapter 10 Metabolic and Molecular Responses of Fish to Hypoxia. in: Richards, J.G., Farrell, A.P., Brauner, C.J. (Eds.), Fish Physiology. Academic Press, pp. 443-485.

Roze, T., Christen, F., Amerand, A., Claireaux, G., 2013. Trade-off between thermal sensitivity, hypoxia tolerance and growth in fish. J Therm Biol. 38, 98-106.

http://dx.doi.org/10.1016/j.jtherbio.2012.12.001.

Stearns, S.C., Kaiser, M., Kawecki, T.J., 1995. The differential genetic and environmental canalization of fitness components in Drosophila melanogaster. J Evolution Biol. 8, 539-557.

https://doi.org/10.1046/j.1420-9101.1995.8050539.x.

Turkmen, S., Zamorano, M.J., Fernandez-Palacios, H., Hernandez-Cruz, C.M., Montero, D., Robaina, L., Izquierdo, M., 2017. Parental nutritional programming and a reminder during juvenile stage affect growth, lipid metabolism and utilisation in later developmental stages of a marine teleost, the gilthead sea bream (Sparus aurata). Brit J Nutr. 118, 500-512.

https://doi.org/10.1017/s0007114517002434.

Vagner, M., Zambonino Infante, J.L., Robin, J.H., Person-Le Ruyet, J., 2007. Is it possible to influence European sea bass (Dicentrarchus labrax) juvenile metabolism by a nutritional conditioning during larval stage? Aquaculture. 267, 165-174. https://doi.org/10.1016/j.aquaculture.2007.01.031.

Vanderplancke, G., Claireaux, G., Quazuguel,P., Huelvan, C., Corporeau, C., Mazurais, D., ZamboninoInfante, J.-L., 2015. Exposure to chronic moderate hypoxia impacts physiological and developmental traits of European sea bass (Dicentrarchus labrax) larvae. Fish Physiol Biochem. 41, 232-242. https://doi.org/10.1007/s10695-014-0019-4.

Villeneuve, L., Gisbert, E., Le Delliou, H., Cahu, C.L., Zambonino Infante, J.L., 2005. Dietary levels of all-trans retinol affect retinoid nuclear receptor expression and skeletal development in European sea bass larvae. Brit J Nutr. 93, 791-801. https://doi.org/10.1079/BJN20051421.

Waddington, C.H., 1942. Canalization of development and the inheritance of acquired characters. Nature.150, 563-565. https://doi.org/doi:10.1038/150563a0.

Wadhwa, P.D., Buss, C., Entringer, S., Swanson, J.M., 2009. Developmental Origins of Health and Disease: Brief History of the Approach and Current Focus on Epigenetic Mechanisms. Semin Reprod Med. 27, 358-368. https://doi.org/10.1055/s-0029-1237424.

Zambonino Infante, J.L., Cahu, C.L., Péres, A., Quazuguel, P., Le Gall, M.M., 1996. Sea bass (Dicentrarchus labrax) larvae fed different Artemia rations: Growth, pancreas enzymatic response and development of digestive functions. Aquaculture. 139, 129-138. https://doi.org/10.1016/00448486(95)01149-8. 
Table 1. Composition of the regimes

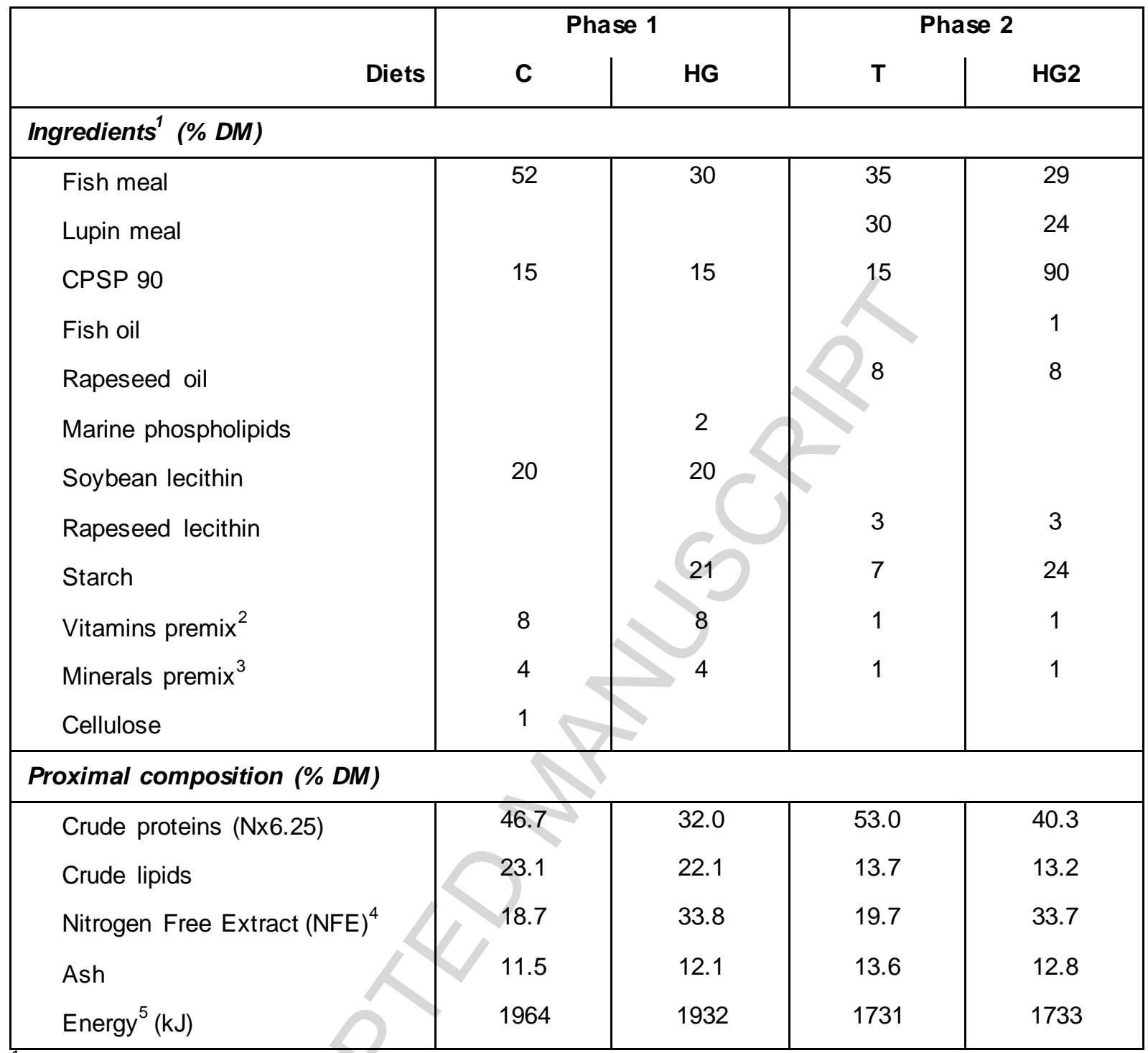

${ }^{1}$ All dietary ingredients were obtained commercially. Fish meal and CPSP 90 [Soluble Fish Protein Concentrate] (Sopropêche, Boulogne sur Mer, France); Soybean lecithin (Ets Louis François, St Maur des Fossés, France); Marine lecithin LC 60 (Phosphotech, St Herblain, France) ; Starch (Roquette, Lille, France).

${ }^{2}$ Composition per $\mathrm{kg}$ of the vitamin mixture: retinyl acetate $1 \mathrm{~g}$; cholecalciferol $2.5 \mathrm{mg}$; all-rac- $\alpha$-tocopherol acetate $10 \mathrm{~g}$; menadione $1 \mathrm{~g}$; thiamin $1 \mathrm{~g}$; riboflavine $0.4 \mathrm{~g}$; D- calcium pantothenate $2 \mathrm{~g}$; pyridoxine $\mathrm{HCl} 0.3 \mathrm{~g}$; cyanocobalamin $1 \mathrm{~g}$; niacin $1 \mathrm{~g}$; choline chloride $200 \mathrm{~g}$; ascorbic acid $20 \mathrm{~g}$; folic acid $0.1 \mathrm{~g}$; biotine $1 \mathrm{~g}$; mesoinositol $30 \mathrm{~g}$.

${ }^{3}$ Composition per kg of the mineral mixture: $\mathrm{KCl} 90 \mathrm{~g}, \mathrm{KIO}_{3} 40 \mathrm{mg}, \mathrm{CaHPO}_{4} 2 \mathrm{H}_{2} \mathrm{O} 500 \mathrm{~g}, \mathrm{NaCl} 40 \mathrm{~g}, \mathrm{CuSO}_{4} 5 \mathrm{H}_{2} \mathrm{O} 3$ g, $\mathrm{ZnSO}_{4} 7 \mathrm{H}_{2} \mathrm{O} 4 \mathrm{~g}, \mathrm{CoSO}_{4} 7 \mathrm{H}_{2} \mathrm{O} 20 \mathrm{mg}, \mathrm{FeSO}_{4} 7 \mathrm{H}_{2} \mathrm{O} 20 \mathrm{~g}, \mathrm{MnSO}_{4} \mathrm{H}_{2} \mathrm{O} 3 \mathrm{~g}, \mathrm{CaCO}_{3} 215 \mathrm{~g}, \mathrm{MgSO}_{4} 7 \mathrm{H}_{2} \mathrm{O} 124 \mathrm{~g}, \mathrm{NaF}$ $1 \mathrm{~g}$.

${ }^{4}$ Calculated as $100-$ (\%crude proteins $+\%$ crude lipids $+\%$ ash)

${ }^{5}$ Calculated as NFE x $16.7 \mathrm{~kJ} / \mathrm{g}$; Crude lipids x $37.7 \mathrm{~kJ} / \mathrm{g}$; Crude proteins x $16.7 \mathrm{~kJ} / \mathrm{g}$ 
Table 2. Forward and Reverse primer sequences used for qPCR.

\begin{tabular}{llll}
\hline Gene & Accession numbers & F.primer & R.primer \\
\hline g6pc & JX073707.1 & AGCTAGGCCTGTGGATGCTA & AAGTGGGCAGCCATGTAGAC \\
gck & JX073704.1 & ATTTGGAGACAACGGTGAGC & CATCAGAACAAGCCTGACCA \\
ef1 $\alpha$ & AJ866727.1 & CTGGAGGGCAGTGAAAAGAT & CATCAAGAGCCTCCAGCAGT \\
\hline
\end{tabular}

Primers were designed from cDNA sequences (g6pc, gck and ef1 $\alpha$ ) available from NCBI websites (Accession numbers listed). Ef1 $\alpha$ was used as reference gene.

Table 3. Specific activities of digestive enzymes and expression of genes involved in glucose metabolism, in 20-days-old larvae fed control diet or high-glucose diet. Data are given as mean \pm S.D. $(n=5)$.

\begin{tabular}{|c|c|c|c|}
\hline & C group & HG group & p-value \\
\hline \multicolumn{4}{|l|}{ Specific activity (mUnit.mg protein ${ }^{-1}$ ) } \\
\hline Trypsin & $42.0 \pm 6.99$ & $19.7 \pm 3.29$ & $p=0.00001$ \\
\hline Amylase & $3890 \pm 395$ & $5252 \pm 395$ & $p=0.00047$ \\
\hline Sucrase & $3.9 \pm 0.38$ & $4.6 \pm 0.64$ & $p=0.00320$ \\
\hline \multicolumn{4}{|l|}{ Gene expression relative to EF-1 } \\
\hline Glucose 6-Phosphatase & $0.93 \pm 0.097$ & $0.65 \pm 0.171$ & $p=0.0134$ \\
\hline GlucoKinase & $0.19 \pm 0.115$ & $0.49 \pm 0.119$ & $p=0.0102$ \\
\hline
\end{tabular}


Table 4. Growth, blood and hepatic parameters, enzymatic assays and gene expression for juvenile fish, fed T or HG2 diets depending on their larval nutritional conditioning (C or HG diet).

Means \pm S.D. with a different superscript letter in a same row were significantly different $(p<0.05)$.

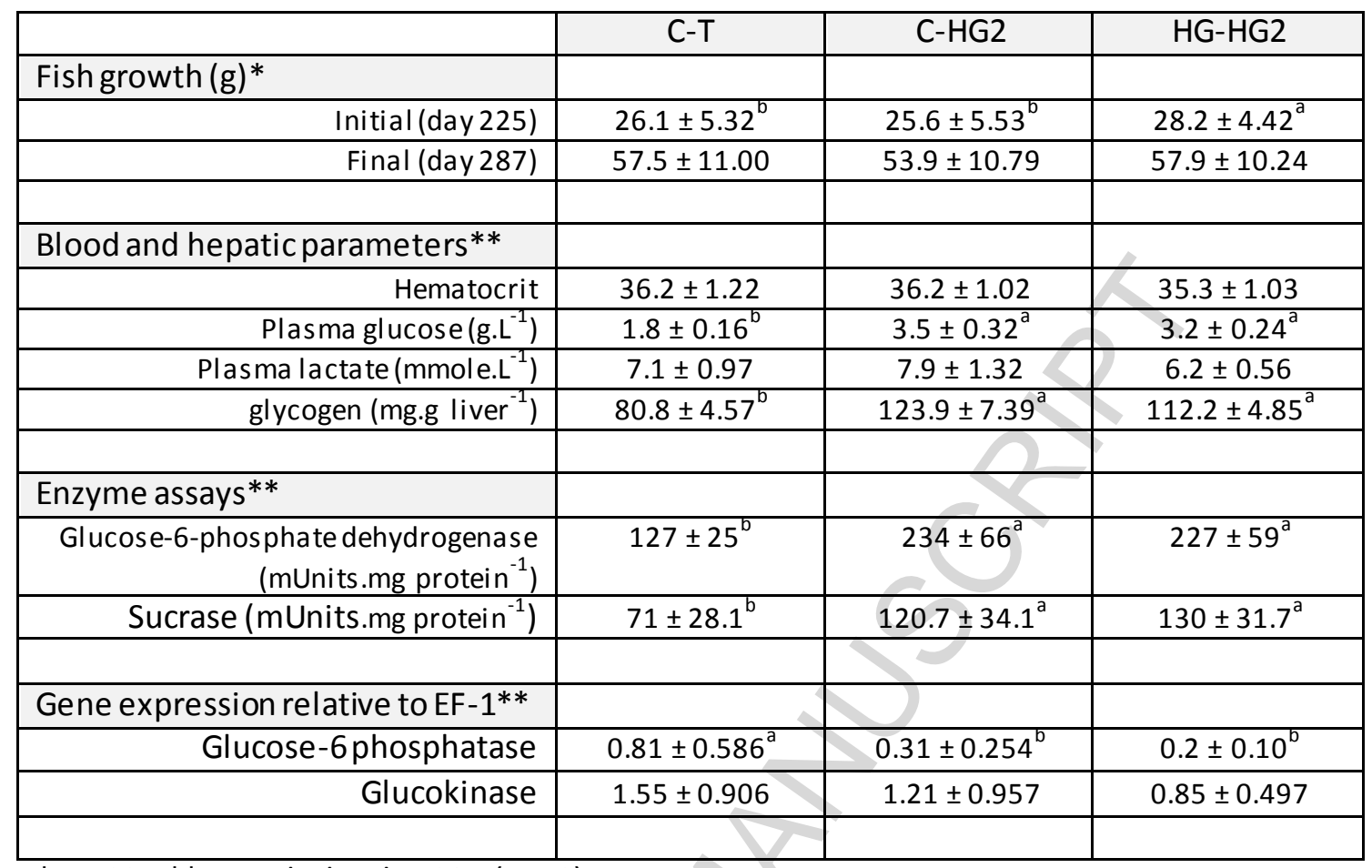

$*_{n=100 ; * *}^{*}$ sampled at day $287(n=12)$ 


\section{Legends of the figures}

Figure 1. Experimental design showing the different dietary sequences and main events from larval to juvenileperiod.

Figure 2. Tolerance to hypoxia challenge test of juvenile sea bass at day 220 , according to their previous larval nutritional conditioning. Number of fish used for the challenge: C-history group, $\mathrm{n}=300$; HG-history group, $\mathrm{n}=300$.

Figure 3. Tolerance to hypoxia challenge test of juvenile sea bass at day 292 , according to their present diet (Tor HG2) and previous larval nutritional conditioning (Cor HG). Number of fish used for the challenge: $\mathrm{C}-\mathrm{T}$ group, $\mathrm{n}=188 ; \mathrm{C}-\mathrm{HG} 2$ group, $\mathrm{n}=88$; $\mathrm{HG}-\mathrm{HG} 2$ group, $\mathrm{n}=88$. 


\section{Highlights}

- A trial to achieve a nutritional programming of the carbohydrate metabolic pathways was conducted on European sea bass larvae from first feeding.

- Six months later, while all the juvenile fish were fed the same standard diet, a challenge test allowed to evidence that fish having been fed high-carbohydrate regime at larval stage performed much better than control.

- After two months of feeding again with a high-carbohydrate diet, such larval nutritional history did not confer any subsequent "advantage" or "disadvantage" to juveniles.

- A second challenge test performed just after indicated that the larval conditioning may fade over time, which should prompt us to reconsider the standard programming strategy used in fish. 


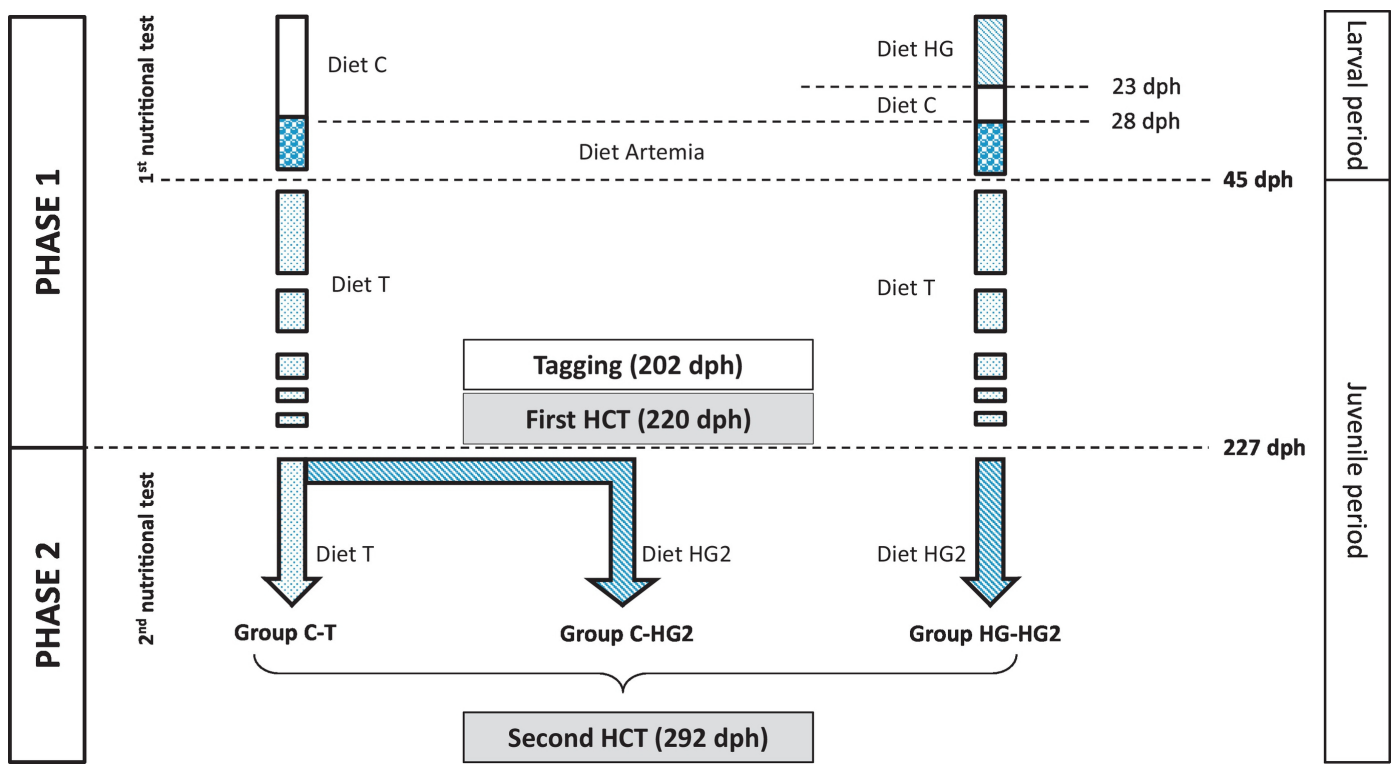

Figure 1 


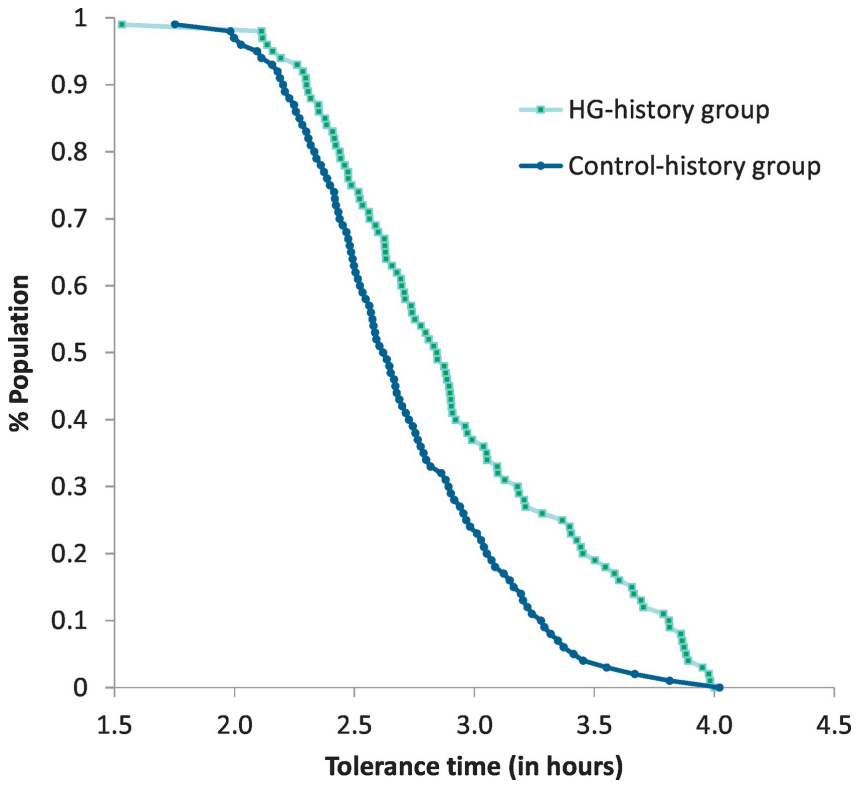

Figure 2 


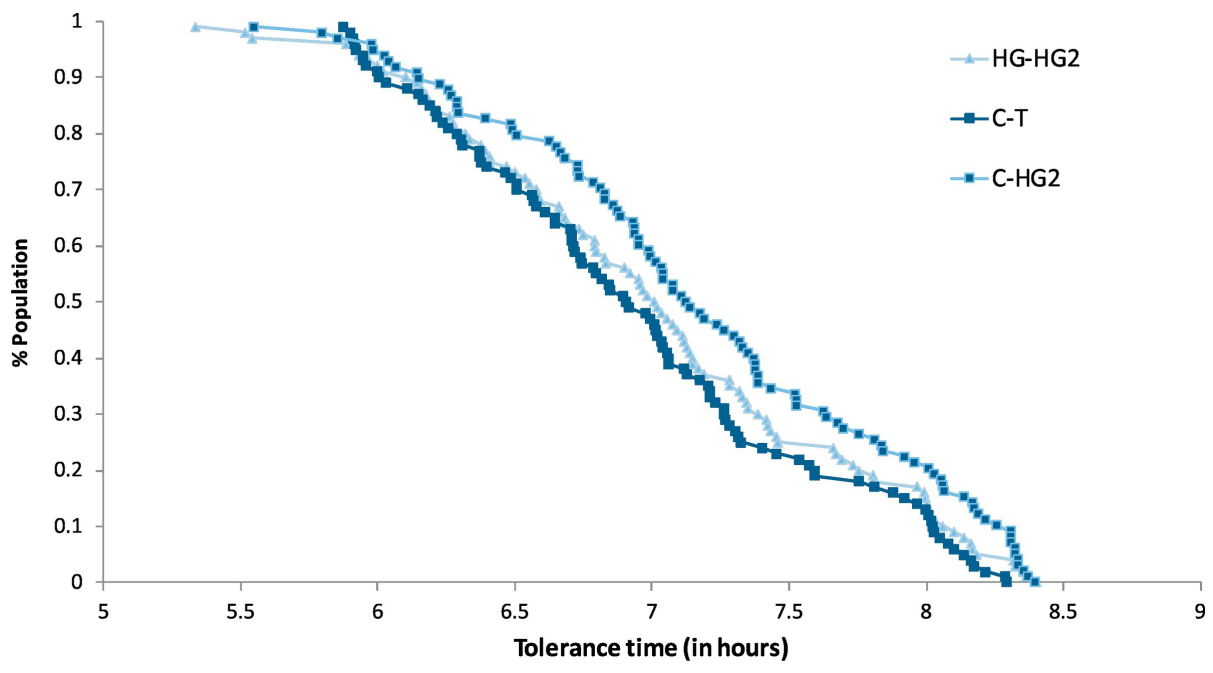

Figure 3 